\title{
Calcifications of the Carotid Siphon-A Common Finding in Infancy and Childhood ${ }^{\star}$
}

\author{
W. W. MEYER and J. LIND \\ From the Paediatric Clinic, Karolinska Sjukhuset, Stockholm, Sweden; and the Institute of Pathology, Mainz, Germany
}

\begin{abstract}
Meyer, W. W., and Lind, J. (1972). Archives of Disease in Childhood, 47, 355. Calcifications of the carotid siphon-a common finding in infancy and childhood. In the tortuous sigmoid segment of the internal carotid artery ('carotid siphon') which is located in the base of the skull, calcific deposits have been shown macroscopically in all 22 children of this series aged 1 to 16 years who died after accidents (11 cases), or after various diseases of a short or longer duration ( 5 and 6 cases, respectively). The calcific incrustations appear first and become most pronounced in the upper part of the carotid siphon, i.e. above the orifice of the ophthalmic artery. In half the cases calcifications were grossly visible in the orifice and proximal segment of this artery as well. Microscopically, the calcific deposits represent incrustations of the subintimal internal elastic layers and adjacent media. The local and general factors probably responsible for these early arterial calcifications and the possible prospective significance of these lesions are discussed.
\end{abstract}

Before entering the intracranial space, the internal carotid artery forms a tortuous sigmoid segment. This segment includes portions of the artery which pass through the carotid canal of the temporal bone ('petrous part') and the cavernous sinus ('cavernous part') (Fig. 1 and colour plate A). Together with the carotid sinus where the internal carotid artery originates, this sigmoid arterial segment represents a predilection site for atherosclerotic lesions and calcific deposits (Dalith, 1968; dei Poli and Žucha, 1940; Dörfler, 1935; Samuel, 1956; Spatz, 1939; Stochdorph and Meessen, 1957). Calcifications have often been found in this arterial segment even in young adults (dei Poli and Žucha, 1940; Dörfler, 1935), which indicates a very early development of these lesions. To find out the gross and microscopical patterns of the initial phases of the calcific deposits, their predominant location, and the age at which they appear, a study of the petrous and cavernous portions of the internal carotid artery in children aged 1 to 16 years has been made.

With regard to the peculiar serpentine course and the significance of both parts of the artery as a predilection site of early pathological lesions, the

\footnotetext{
Received 4 October 1971.

^Supported by Semper AB, Stockholm, and the Association for the Aid of Crippled Children, New York, U.S.A.
}

petrous and cavernous portions have been considered as a structural and functional entity. In the following text it is abbreviated as 'carotid siphon' of the internal carotid artery, a name that has been used by many authors (Fisher, 1957; Spatz, 1939; Stochdorph and Meessen, 1957).

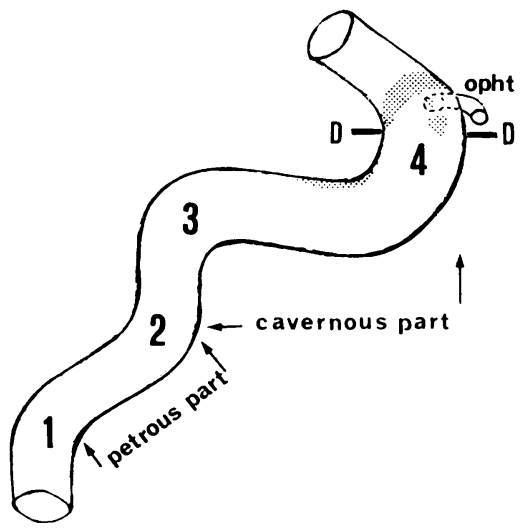

FIg. 1.- Schematic presentation of the right carotid siphon including the petrous and cavernous parts of the internal carotid artery. The numbers (1-4) indicate the corresponding curvatures of the siphon. $D-D=$ penetration of the dura mater. Opht =origin of the ophthalmic artery. The predilection sites of the early calcifications are dotted. 


\section{Materials and Methods}

The siphon of the internal carotid artery, i.e. the petrous and cavernous portions of this vessel, was examined in 22 children who died between the ages of 12 months and 16 years. In these consecutive unselected necropsy cases (December 1969 to July 1971) the central basal area of the skull, including the sella turcica, the neighbouring parts of the sphenoid bone, and both pyramids, was sawn out and removed from the body. The carotid canal was then opened with short strong scissors and the anterior clinoid process removed. The dura mater was incised along the course of the cavernous part of the carotid siphon, i.e. on the lateral surface of the sphenoid bone and around the entrance of the siphon in the intracranial space. Then both siphons were removed and dissected free from the remaining parts of the venous sinus and dura mater. For gross demonstration of calcific deposits, a modified Von Kossa technique was used (Meyer and Stelzig, 1969a, b). The siphons were washed three times in distilled water for about 5 minutes each time. Then they were placed in a fresh aqueous solution of silver nitrate for 24 hours and kept in the dark, to ensure a thorough diffusion of $\mathrm{AgNO}_{3}$. The segments were opened longitudinally after this time for better exposure of the luminal layer of the artery.

The calcium phosphates and carbonates are converted into their silver equivalents by the Von Kossa reaction. The exposure to light causes the subsequent reduction to black metallic silver and results in a black coloration of phosphate and carbonate deposits in the tissue, i.e. arterial wall (see Fig. 3). Thus, not the calcium itself but the deposition of insoluble phosphates and carbonates is shown with the Von Kossa reaction. In human tissues, however, insoluble phosphates and carbonates are nearly always those of calcium, and the method is usually regarded as sufficiently specific for this element (Pearse, 1953). In some cases the calcifications in the carotid siphon were also shown grossly by staining of the whole arterial segment with alizarin (see colour plate B). Other methods of identification of calcium were also used in this study (see microscopical findings). They confirmed the reliability of the Von Kossa technique for gross demonstration of calcific incrustations in the human arteries. For microscopical examination, cross or longitudinal, step-by-step or serial cryostat (frozen) sections were used.

\section{Results}

Anatomy. At the level of the lower end of the carotid canal the internal carotid artery forms its first curve, enters the canal in the petrous portion of the temporal bone, and runs horizontally in an anteromedial direction. This is the 'petrous part' of the internal carotid artery (Fig. 1, colour plate A). Above the internal opening of the carotid canal the artery describes a second curve upwards and enters the sinus cavernosus. Here begins the 'cavernous part' of the artery which first rises vertically along the body of the sphenoid bone. On reaching the posterior clinoid process the artery makes a third curve and continues horizontally forwards with either a slight upward or downward inclination, lying in the carotid groove of the sphenoid bone. In the anterior portion of the carotid groove, i.e. at the level of the anterior clinoid process, the vessel changes its direction sharply by making a fourth curve at an angle of about $180^{\circ}$ and perforates the dura mater (Fig. 1, colour plate A). The upper part of this curve is located above the dura mater and is partly covered by the optic nerve which crosses the artery and here lies close to the anterior and upper wall of the curvature. Immediately above the perforation of the dura mater the ophthalmic artery originates from the anteromedial wall of the fourth curve.

As mentioned above, the sigmoid tortuous arterial segment, which includes both the petrous and cavernous portions of the internal carotid artery, is called the 'carotid siphon' in the following text.

Angiograms of 12 human fetuses at midterm showed that the curves of the carotid siphon were still flat (Fig. 2), whereas in the newborn the siphon

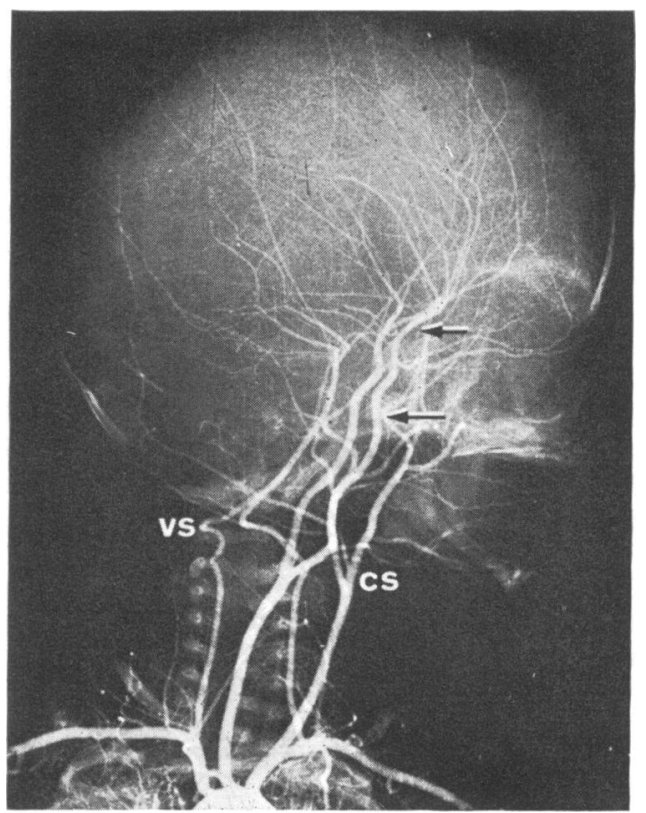

FIG. 2.-Angiogram of the cerebral arteries of a $27 \mathrm{~cm}$ long fetus. The curvatures of both carotid siphons (between arrows) are still flat. (See Colour Fig. A.) Enlarged $\left(\times 1 \frac{1}{1}\right)$. CS: left carotid sinus; VS: siphon of the right vertebral artery. (KS II/3 59, Storch; $C R L$ $=15 \mathrm{~cm}$ ) 


\section{Calcifications of the Carotid Siphon-A Common Finding in Infancy and Childhood}

is already well developed and has a curved aspect, as seen in children (colour plate A) and young adults. Thus, the tortuosity of the carotid siphon increases during the last months of gestation.

Microscopy. The subendothelial elastic structures are strongly developed in the carotid siphon and consist of two layers.

(1) A thicker internal elastic layer: as in the focal intimal proliferations of the cerebral arteries (Stehbens, 1960), this layer obviously develops by confluence of longitudinally oriented elastic fibres which initially appear on the luminal surface of the primary internal elastic membrane and can be discerned in cross and tangential sections even in the later stages of formation of this layer. Thus, the development of this secondary elastic layer corresponds to the formation of the secondary internal elastic lamella of other peripheral muscular arteries (Lang and Nordwig, 1966; Walsh, Meyer, and Lind, 1972). The earlier and stronger development of the secondary elastic layer in the carotid siphon may be related to high growth rate of the human cranium and brain during fetal development and in the first year of life (see Discussion).

(2) The thinner outer layer which displays the structural characteristics of the typical primary fenestrated internal elastic membrane. Only small irregularly distributed interruptions can be discerned in the course of this membrane. No wide circular gaps which are regularly present in other peripheral muscular arteries (Meyer and Stelzig, $1969 \mathrm{a}, \mathrm{b})$ have been found in the carotid siphon.

Thick intimal cushions are present on the inner concave bands of the curvatures of the carotid siphon even in the first years of life (Dörfler, 1935). In contrast, no preformed intimal cushions or other structural peculiarities have been found in the areas of the carotid siphon where the calcifications appear first, i.e. above the orifice of the ophthalmic artery (see macroscopical findings). On the longitudinal sections only a slight thinning of the media and subintimal elastic structures could be discerned here in comparison with the proximal vascular segment.

The medial coat of the carotid siphon consists of circularly oriented muscle cells. However, in the curvatures the regular circular course of the muscular elements is disturbed and the musculature is often arranged obliquely or irregularly. Only a few fine elastic fibres are present in the media. The adventitia consists of fine collagenous and poorly developed elastic networks.
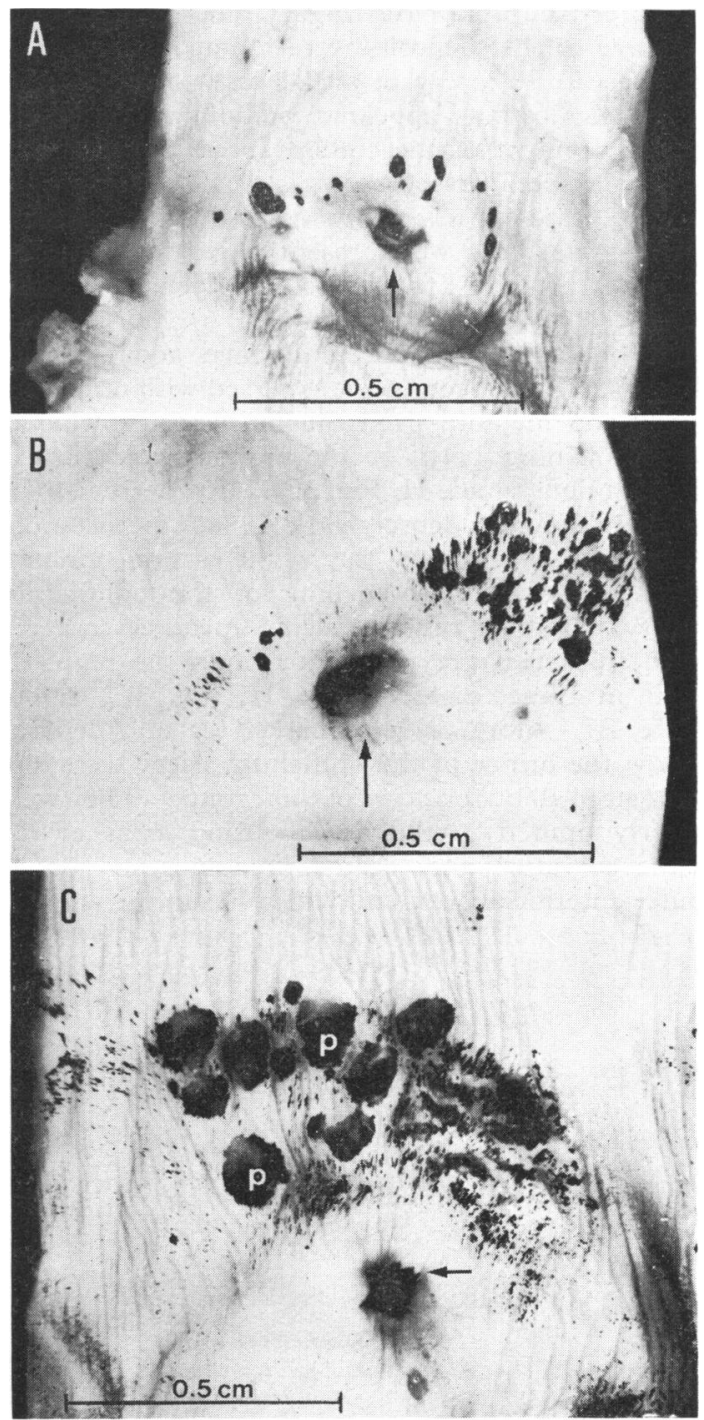

Fig. 3.-A-C: Gross demonstration of calcific incrustations (black), in the upper part of the carotid siphon. Modified Von Kossa reaction. ( $A$ ) Early scattered incrustations above the branching of the ophthalmic artery (arrow) and in its orifice (grade I lesion). 13-month-old child. (B) Part of arterial circumference above and lateral to the branching of the ophthalmic artery (arrow) interspersed with polygonal and fine linear incrustations (grade II lesion). 8-year-old girl who died in a traffic accident. (C) Whole circumference of same arterial segment is densely interspersed with calcific incrustations (grade III lesion). Larger calcific plaques ( $p$ ) are partly covered with a greyish tissue layer. Calcific incrustations are also seen in the orifice of the ophthalmic artery (arrow), and below it. 10-year-old boy who died after a traffic accident (see colour plate $B$ ). 
Macroscopical findings. The Von Kossa positive calcific deposits were found in the siphon of the carotid artery in all 22 cases of this series. The calcifications appeared predominantly in the upper segment of the siphon above the orifice of the ophthalmic artery.

In 7 cases a few black dot-like or fine linear incrustations only were present above the branching of this artery (Fig. 3A). Such changes were classified as grade I lesions. In 6 other cases a part of the arterial circumference above and/or lateral to the orifice was interspersed with numerous small and medium-sized calcific deposits, whereas the remaining parts of the siphon were free of gross lesions (grade II, Fig. 3B). In the remaining 9 cases numerous densely packed black incrustations were spread out over the whole arterial circumference above the branching of the ophthalmic artery. Larger raised calcific plaques covered with thickened greyish intima could be regularly seen in these cases (grade III, Fig. 3C, colour plate B). More or less marked calcific deposits below the orifice of the opthalmic artery were also present in all but one case of this group. They were mostly limited to the neighbouring areas of the same curvature and located predominantly on its outer anterior convex wall which lies in the anterior part of sulcus caroticus of the sphenoid bone. Scattered, fine dot-like calcific incrustations were not infrequently present also at the opposite inner bend of this curvature, which appears on a longitudinally-opened retracted artery, as a rim-like fold protruding in to the arterial lumen. In only 2 cases were pronounced incrustations spread out over the more proximal segments of the siphon. The calcification pattern, i.e. the extent and severity of lesions, were in each case approximately the same in both siphons.

Grade I lesions were found in 5 children of younger age groups (12 months to 5 years of age), and only in 2 children aged 14 and 16 years (Table).

TABLE

Severity of Calcifications of Carotid Siphon in Individual Age Groups

\begin{tabular}{c|c|c|c|c}
\hline $\begin{array}{c}\text { Age Groups } \\
(\mathrm{yr})\end{array}$ & $\begin{array}{c}\text { Total No. } \\
\text { of Cases }\end{array}$ & $\begin{array}{c}\text { Grade I } \\
\text { Lesions }\end{array}$ & $\begin{array}{c}\text { Grade II } \\
\text { Lesions }\end{array}$ & $\begin{array}{c}\text { Grade III } \\
\text { Lesions }\end{array}$ \\
\hline $1-2$ & 5 & 3 & 2 & - \\
$3-5$ & 6 & 2 & -5 & 4 \\
$6-16$ & 11 & 2 & 4 & 5 \\
\hline Total & 22 & 7 & 6 & 9 \\
\hline
\end{tabular}

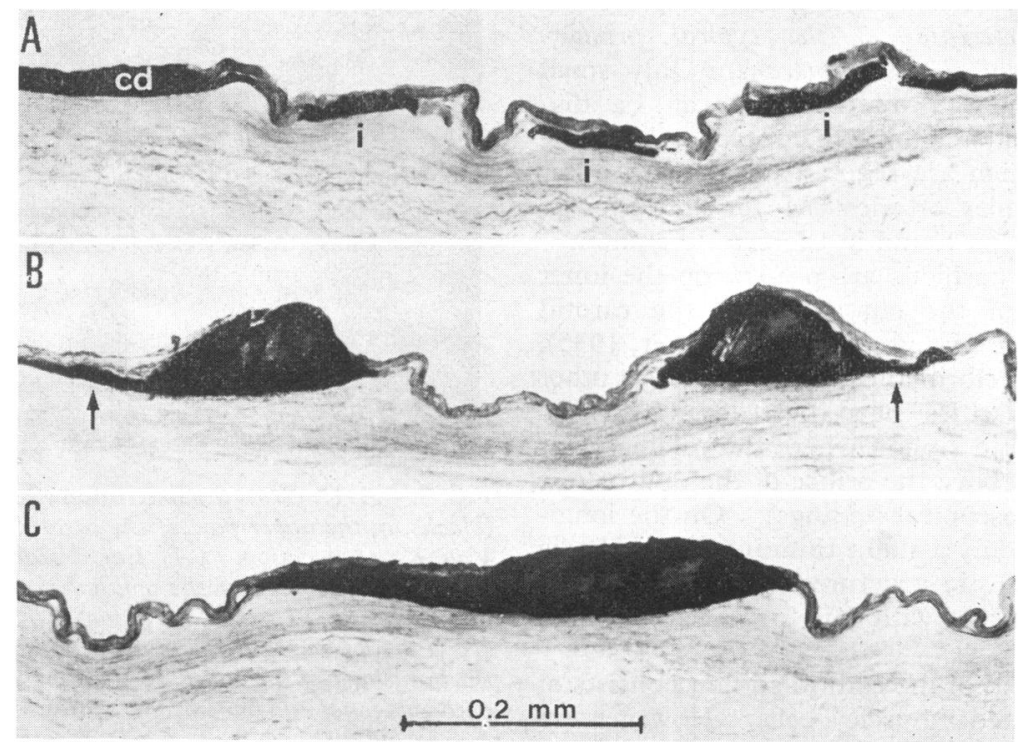

FIG. 4.-A-C: Microscopical patterns of the calcific incrustations in the carotid siphon of a 3-year-old boy who died in a traffic accident. Von Kossa reaction and Gomori's aldehyde fuchsin stain for elastic tissue. ( $A$ ) Early calcific incrustations ( $i$, black) are predominantly located in the interrupted primary internal elastic membrane. The noncalcified secondary internal elastic layer is seen above the lesions. However, to the left this layer is involved in a calcific deposit $(c d)$ also. $(B)$ and $(C)$ Larger protruding calcific deposits involving both internal elastic layers. In the periphery of the plaques, only the primary internal elastic membrane is calcified (B: arrows). 

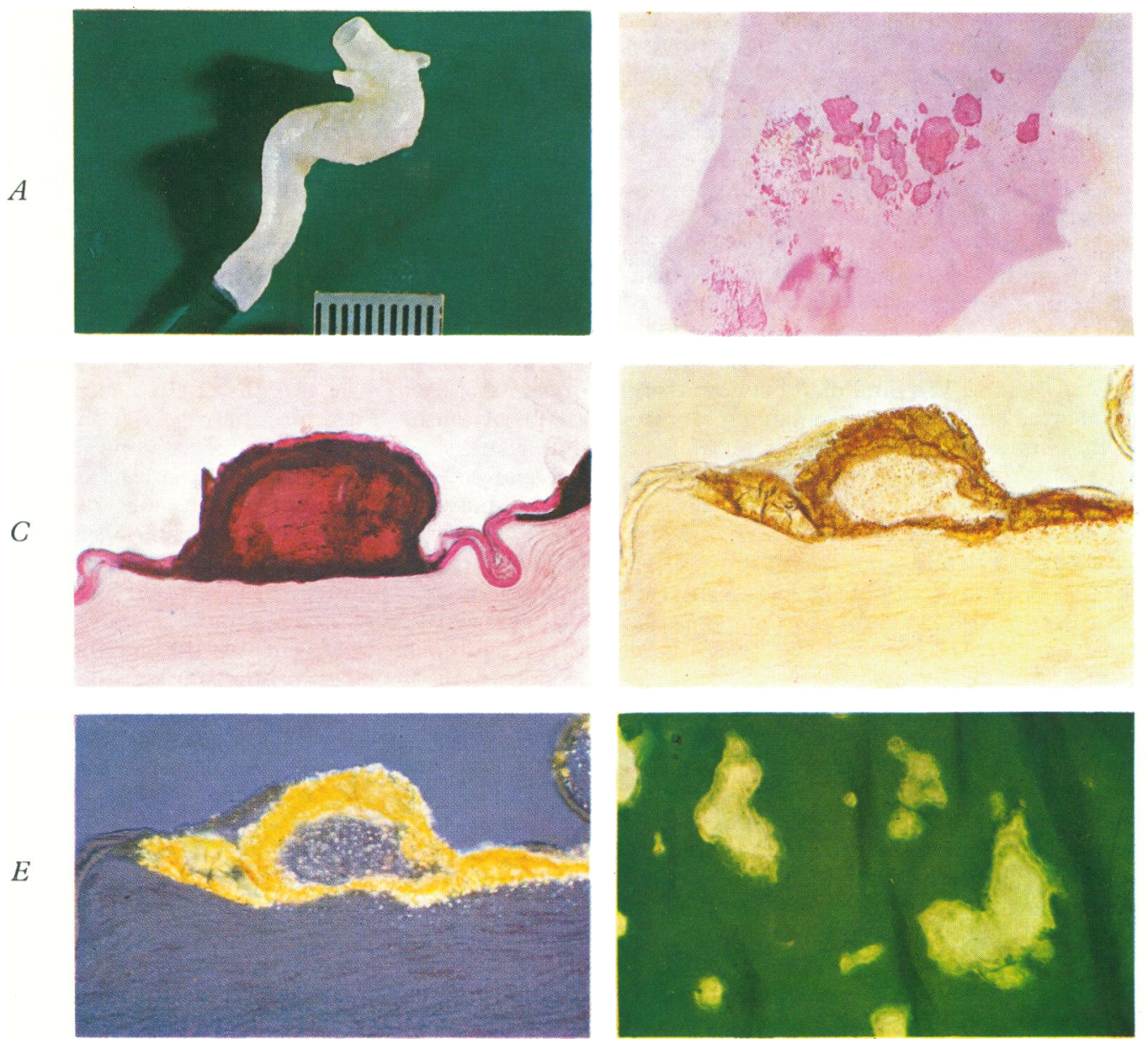

PLATE A.-Siphon of right internal carotid artery of a 4-year-old boy. The siphon was removed after fixation in formalin at a filling pressure of $90 \mathrm{mmHg}$. Only the distal part of the petrous portion of the internal carotid artery is seen below the 2nd curvature. The cross-section of the ophthalmic artery is seen on the outer (anterior) surface of the upper (fourth) curvature. On the opposite wall of the same curvature, a part of the adjacent dura mater indicates the level at which the internal carotid artery enters in the intracranial space (mm scale below). (See Fig. 1.)

PLATE B.-Marked calcific deposits stained red with alizarin are seen in the left carotid siphon above the origin of the

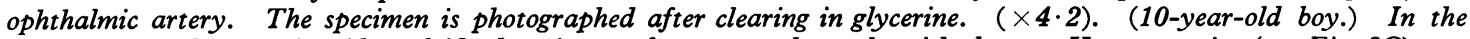
siphon of the opposite side, calcific deposits are demonstrated grossly with the von Kossa reaction (see Fig. 3C).

Plate C.-Larger calcific deposit (black and dark brown) in the carotid siphon of a 3-year-old infant. On both sides of the deposit, the noncalcified parts of both the inner and outer elastic layers (violet) are seen. (Von Kossa reaction and Gomory's stain for elastic tissue $\times 330$.)

Plates D and E.-Identification of calcium in larger plaque-like lesions of carotid siphon by Voigt's technique. After exposure to $N, N$-naphtalylhydroxylamine sodium salt, the deposits assume a yellow-brownish coloration $(D)$ and appear densely interspersed with anisotropic crystals in polarized light $(E) . \quad$ A 2-year-old girl. $(\times 330$.

FIG. F.-Numerous mineralizations of different size and density (light green and yellowish) are seen in the microradiograph of the wall of the carotid siphon of a 3-year-old boy who died in a traffic accident. The microradiograph was made with 'Micro-60' equipment, produced by C. H.F. Müller, Hamburg. ( $(\times 53$.) 
The youngest child of this group (12 months of age) died of a hydrocephalus internus. Two children, aged 4 and 16 years, died after traffic accidents. In the other cases pyaemia with multiple lung abscesses, acute respiratory infection, exploratory laparotomy, and the Duchenne type of muscular dystrophy were the causes of death.

Grade II lesions were found in 4 children who died after traffic accidents $\left(2,7,7 \frac{3}{4}\right.$, and 8 years old respectively), in a 9-year-old child with an atrial septal defect, and in a 2-year-old with acute panmyelopathia and agranulocytosis.

Grade III lesions were observed in 9 children aged 3 to $13 \frac{1}{2}$ years. 5 children of this group (aged $23,3,9,10$, and 12 years) died between 0 and 7 days after accidents. In the remaining 4 cases asphyxia by alimentary bolus, Fallot's tetralogy, a generalized phlebothrombosis of unknown origin, and chronic glomerulonephritis were the causes of death. The ages of these children were $3,5,5 \frac{1}{2}$, and $13 \frac{1}{2}$ years respectively.

The extension and severity of the lesions increase obviously with growth (Table). In the age group 1-2 years no grade III lesions have been found. In the age groups 3-5 years and 6-16 years, the majority of cases showed grade II and III lesions, respectively. However, the variations in the extension of the lesions were considerable in each age group, and the relation between the severity of calcification and growth could not be proved statistically in the small number of cases studied.

In half of the 22 cases, calcific incrustations were seen macroscopically also in the orifice and in the proximal part of the ophthalmic artery.

Microscopical findings. The fine black incrustations which become visible after the Von Kossa reaction on the luminal surface of the siphon represent, microscopically, deposits in the subendo- thelial elastic layer. They initially develop in the primary internal elastic membrane, but in most lesions the secondary elastic layer, which covers the primary membrane, is also involved (Fig. 4A-C). Early calcifications are often located on the crests of the wavy internal elastic layer. With the further extension of the calcific deposits, the usual rhythmical wavy pattern of this elastic layer becomes disturbed and gradually flattens (Fig. 4C).

When the Von Kossa method is applied to the whole arterial segment, i.e. macroscopically, only the outer layer of the calcific deposits turns black (see Fig 7B). The precipitation of the black metallic silver obviously first occurs in this layer and prevents the exposure to light of the central parts of the plaques. Therefore these parts retain their initial structure, and consist microscopically of a transparent, unstained vitreous substance (Fig. 7B). Many dark lines, which are obviously fractures in the hard crystalline material, are seen in the midst of these deposits. The larger calcific plaques often crumble when cut and then their crystalline structure is even more clearly visible. After additional treatment of the microscopical sections with the silver nitrate solution, the deeper parts of the deposits react also, and the lesions then become completely black (Fig. 5, colour plate C).

It has been shown with serial cryostat sections that even in the smallest Von Kossa positive lesions of the carotid siphon the calcium can be identified by Voigt's histochemical method (1957). With this technique, yellow anisotrophic crystals are formed within the calcium deposits after exposure of microscopical sections to a solution of $\mathrm{N}, \mathrm{N}-$ naphtalylhydroxylamine sodium salt (Fig. 6A-B, colour plates D and E). Voigt (1957) has shown that iron, copper, lead, zinc, cobalt, and mercury deposited in animal tissues, even in large quantities,

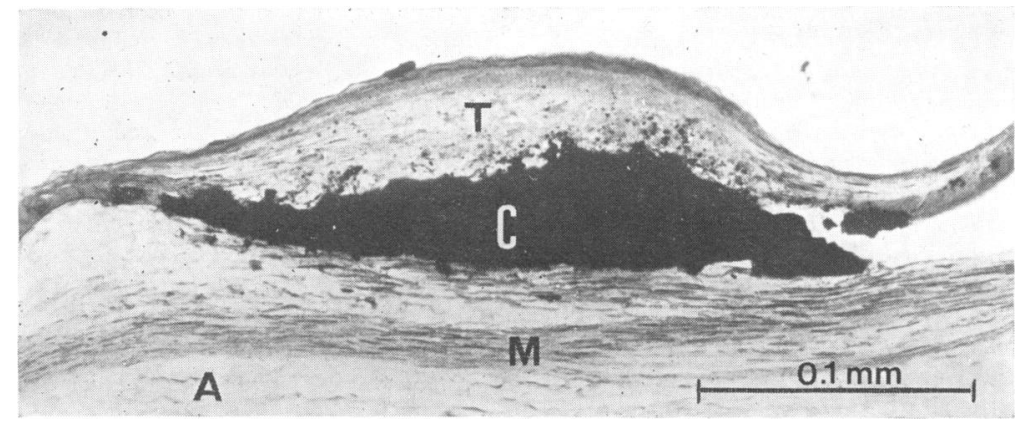

FIG. 5.-Larger calcific deposit (black, $C$ ) in the wall of the carotid siphon covered by a thick layer of the connective tissue (T). M, media; $A$, adventitia. 12-year-old boy who died after an accident. 


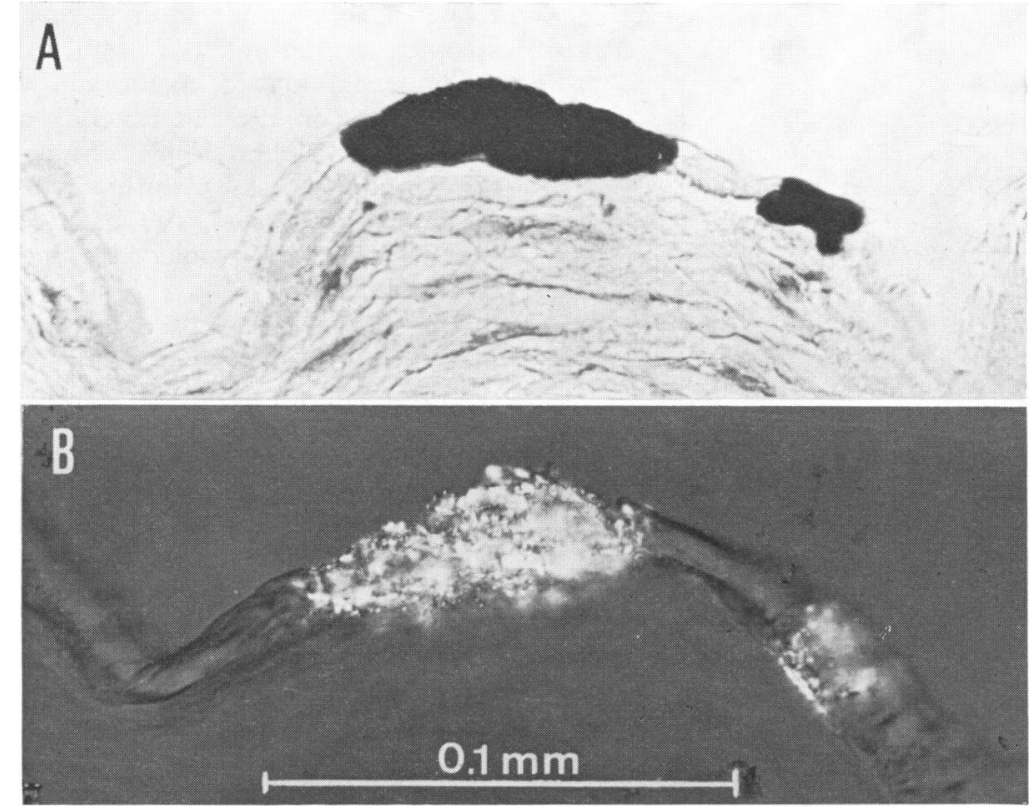

Fig. 6.-A and B: Smaller early calcific deposits in the internal elastic layer of the carotid siphon comparatively shown in cryostat serial sections by Von Kossa's $(A)$ and Voigt's technique $(B)$. Von Kossa positive lesions $(A$, black-stained parts of the elastic layer) become anisotrophic in the next cryostat section when Voigt's technique is used $(B)$. 2-year-old girl.

do not react with naphthalhydroxame-acid, and no anisotropic material is formed in the deposits of these elements.

Further reactions also confirm the marked calcium content of the lesions. Numerous gypsum crystals are formed in the plaques upon exposure of microscopical sections to sulphuric acid (Fig. 7A). In larger deposits, numerous gas bubbles appear when concentrated hydrochloric acid is added (Fig. 7B, C).

As in the other arterial provinces, the extent of the mineralization in the affected segment of the siphon can also be shown by microradiography (colour plate F). On microradiographs, the pattern of mineralization, i.e. the size and shape of the calcified parts, is exactly the same before and after the Von Kossa reaction. However, microradiographs of greater contrast can be obtained after the Von Kossa reaction from the same arterial segment.

The larger calcific deposits protrude markedly in the arterial lumen (Fig. 4B, 5). This is probably a a postmortem phenomenon due to the retraction of both the underlying and neighbouring unaffected parts of the arterial wall. However, the larger calcific plaques which are often covered with a thick connective tissue layer (Fig. 5) may, even in vivo, be raised over the intima and cause a marked deformation of the usually smooth luminal surface of the artery.

In the ophthalmic artery, the calcific incrustations show the same microscopical characteristics as the calcifications of the carotid siphon.

\section{Discussion}

The regular occurrence of calcific deposits in the siphon of the internal carotid artery in children who died in accidents, and who were probably healthy before, suggests that these deposits could be a normal structural peculiarity accompanying growth. However, the severity of the calcific incrustations and a rather irregular distribution pattern of the mineralization make it more likely that they represent a pathological process.

Local and general factors could be responsible for its development. The tortuous pattern of the affected arterial segment may represent a local structural factor and be associated with a higher haemodynamic load, i.e. a greater wall tension, as compared with the other arteries of the same size but of a straight course. This is especially true of 


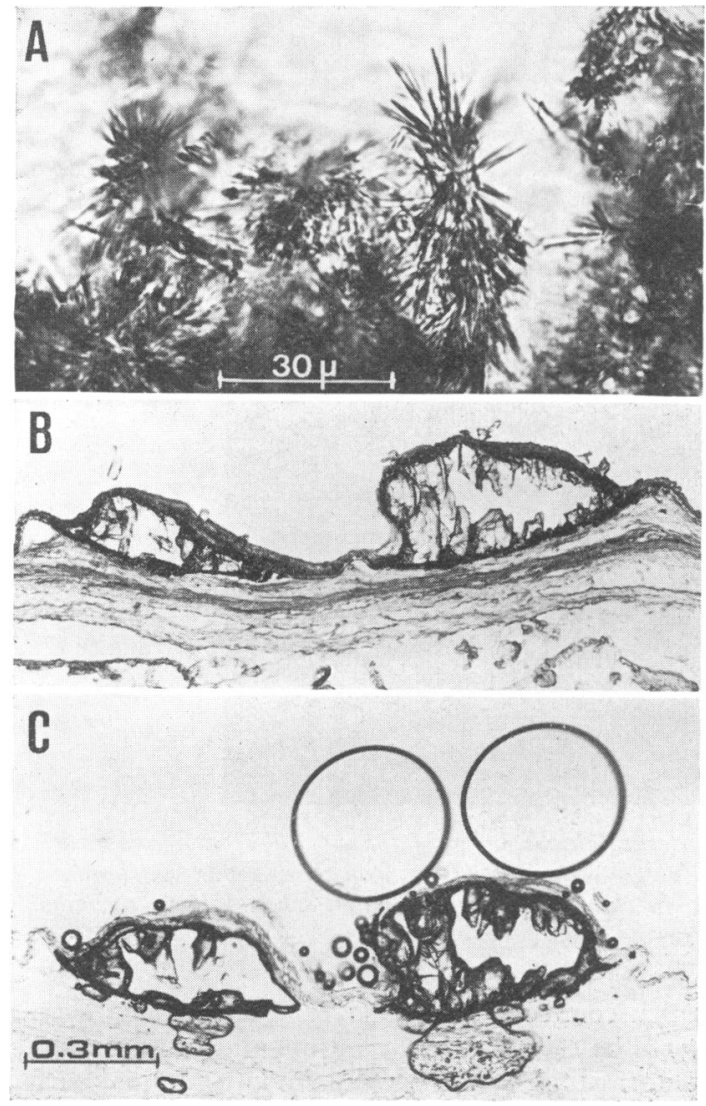

Fig. 7.-A-C: Identification of calcium in the lesions of the carotid siphon. (A) Numerous gypsum crystals appear in the deposits when concentrated sulphuric acid is added to the microscopical slide. (B) Two larger calcific plaques of the carotid siphon, consisting of a crystalline, partially split material. Only a narrow peripheral layer of the plaques is stained black after the gross demonstration of calcifications by the Von Kossa reaction. (See Results.) (C) Numerous gas bubbles (obviously carbon dioxide) appear in the same deposits and in their vicinity, when concentrated hydrochloric acid is added to the microscopical section. (A 12-year-old boy who died after an accident.)

the area above and below the origin of the ophthalmic artery where the calcifications appear first and achieve their greatest extent and severity. This area represents the outer wall of the fourth curve, the sharpest of the carotid siphon, where the blood flow is deflected through an angle of approximately $180^{\circ}$. Thereby, the affected outer wall of this curvature may permanently be subject to a considerable centrifugal force, which arises here when the blood stream is diverted. It seems to be of comparable interest that in the tortuous splenic arteries of the adults, calcifications of the internal elastic membrane appear also predominantly on the outer bends of the curvatures (Meyer and Weber, 1968). Since the tortuosity of the siphon increases during the last months of gestation (see above), the haemodynamic load on the arterial wall would also increase with fetal development.

The high rate of prenatal and postnatal brain growth could also be a factor which favours the development of arterial calcifications. The striking absolute increase in brain weight during the first year of life $(500 \mathrm{~g})$ presupposes an adequate growth of the cerebral arteries, which already in fetal life assume a larger calibre earlier than the vessels of other organs, and therefore become subject, earlier, to a higher total wall tension (Law of Laplace). The higher tension may cause some changes in the elastic elements of the carotid siphon, which could then be followed by calcific incrustation. However, no structural changes could be discerned with the light microscope in the affected area, which could favour the calcific deposits.

Since the affected area lies close to the optic nerve, an injury to the arterial wall may arise here when the pulse wave is transmitted and part of the arterial wall is pressed against the nerve. As many investigations have shown, the 'counterpressure' of the surrounding tissues of a higher or different density can influence the site and shape of the arterial lesions (Meyer, 1964; Polàček and Zechmeister, 1968).

Experimental studies carried out by Selye et al. (Grasso and Selye, 1962; Selye, 1962; Selye, Jean, and Veilleux, 1960) show that the deposition of calcium in the tissues can be the result of an interaction of local and general factors. The administration of parathyroid hormone and vitamin D derivatives results in the mobilization of the calcium from the skeleton, and in large doses these substances cause tissue calcifications without additional localizing factors. Small doses of the same 'calcifying agents' act as 'sensitizers' and induce 'a state of altered tissue reactivity' in which the affinity for calcium of several tissues is increased, and for which the term 'calciphylaxis' has been proposed. In this state, calcific deposits can be produced in different tissues or organs at will by administration of other substances ('challengers'), which interfere with local tissue metabolism. In rabbits rendered calciphylactic, administration of ferric oxide saccharate results in deposition of calcium predominantly in the walls of coronary arteries. Intimal proliferation then ensues which 
narrows the lumen of these vessels and causes disseminated coronary infarction (Grasso and Selye, 1962). Similar changes in the coronaries are seen in the idiopathic arterial calcification of infancy (Moran and Becker, 1959). In a calciphylactic state a mild mechanical trauma also acts as a challenger (Selye et al., 1960). Thus, a higher haemodynamic strain could probably play a similar role and promote the calcific incrustation in the arterial segments which are subject to a higher wall tension.

No data exist which would suggest that the prophylactic administration of vitamin $\mathrm{D}$ could induce a state comparable with the calciphylaxis in children. However, since even small prophylactic doses influence calcium metabolism and favour the deposition of calcium in bones, it seems probable that extraosseous calcific deposits may also be stimulated at the same time. This could be especially true for the arterial segments which in infancy are subject to a relatively higher haemodynamic load, and in which local structural changes arising from wear and tear probably occur during the early stages of growth.

The pronounced calcific deposits which develop early in childhood could impair the normal remodelling of the arterial tube during growth (Dalith, 1968; Gillman, 1968), and in this way favour the development of later pathological changes. In this connexion it seems to be of interest that the thromboatherosclerotic occlusions occur often in the same segment of the carotid siphon in which the calcifications appear early in childhood, i.e. at the level of the orifice of the ophthalmic artery (Hultquist, 1942). However, the interaction of the calcific incrustations with the atherosclerotic changes in the carotid siphon is still to be clarified.

\section{REFERENCES}

Dalith, F. (1968). Embryological aspects of atherogenesis. Annals of the New York Academy of Sciences, 149, 865.

Dörfler, J. (1935). Ein Beitrag zur Frage der Lokalisation der Arteriosklerose der Gehirngefässe mit besonderer Berücksichtigung der Arteria carotis interna. Archiv für Psychiatrie und Nervenkrankheiten, 103, 180.

Fisher, C. M. (1957). Cerebral thromboangiitis obliterans. Medicine, 36, 169.
Gillman, T. (1968). On the possible roles of arterial growth, remodeling, repair, and involution in the genesis of arterial degeneration. Annals of the New York Academy of Sciences, 149, 731.

Grasso, S., and Selye, H. (1962). Calciphylaxis in relation to the humoral production of occlusive coronary lesions with infarction. Fournal of Pathology and Bacteriology, 83, 495.

Hultquist, G. T. (1942). Thrombose und Embolie der Arteria carotis und hierbei vorkommende Gehirnveränderungen (Stockholm). Jena, G. Fischer.

Lang, J., and Nordwig, A. (1966). Úber die Membrana elastica interna von Arterien muskulären Typs. Zeitschrift für Zellforschung und mikroskopische Anatomie, 73, 313.

Meyer, W. W. (1964). Uber die rhythmische Lokalisation der atherosklerotischen Herde im cervicalen Abschnitt der Vertebralarterie. Beiträge zur pathologishen Anatomie und zur allgemeinen Pathologie, 130, 24.

Meyer, W. W., and Stelzig, H. H. (1969a). A simple method for gross demonstration of calcific deposits in the arteries. Angiology, 20, 423.

Meyer, W. W., and Stelzig, H. H. (1969b). Calcification patterns of the internal elastic membrane. Calcified Tissue Research, 3, 266.

Meyer, W. W., and Weber, G. (1968). Calcinose und Spaltensystem der inneren elastischen Membran der geschlängelten Milzarterien. Virchows Archiv Pathologische Anatomie, 345, 292.

Moran, J. J., and Becker, S. M. (1959). Idiopathic arterial calcification of infancy. American fournal of Clinical Pathology, 31, 517.

Pearse, A. G. E. (1953). Histochemistry: Theoretical and Applied, p. 382. Churchill, London.

Polàček, P., and Zechmeister, A. (1968). The occurrence and significance of myocardial bridges and loops on coronary arteries. University J.E. Purkynè, Brno.

dei Poli, G., and Žucha, J. (1940). Beiträge zur Kenntnis der Anomalien und der Erkrankungen der Arteria carotis interna. Zentralblatt für Neurochirurgie, 5, 209.

Samuel, K. C. (1956). Atherosclerosis and occlusion of the internal carotid artery. Fournal of Pathology and Bacteriology, 71, 391.

Selye, H. (1962). Calciphylaxis. University of Chicago Press, Chicago.

Selye. H., Jean, P., and Veilleux. R. (1960). Role of local trauma in production of cutaneous calcinosis by dihydrotachysterol. Proceedings of the Society for Experimental Biology and Medicine, 104, 409.

Spatz, H. (1939). Pathologische Anatomie der Kreislaufstörungen des Gehirns. Zeitschift für die gesamte Neurologie und Psychiatrie, 167, 301.

Stehbens, W. E. (1960). Focal intimal proliferation in the cerebral arteries. American fournal of Pathology, 36, 289.

Stochdorph, O., and Meessen, H. (1957). Die arteriosklerotische und die hypertonische Hirnerkrankung. In Handbuch der speziellen pathologischen Anatomie und Histologie, Bd. 13, Th. IB, p. 1465. Springer, Berlin.

Voigt, G. E. (1957). Ein neuer histotopochemischer Nachweis des Calciums (mit Naphtalhydroxamsäure). Acta histochemica, 4, 122.

Walsh, Z., Meyer, W. W., and Lind, J. (1972). The Human Fetal and Neonatal Circulation. Dynamics and Structure. (In the press.) Thomas, Springfield, Illinois.

Correspondence to Professor John Lind, Department of Paediatrics, Karolinska Hospital, 10401 Stockholm 60 , Sweden. 